\title{
Using Business Theory to Motivate Undergraduate Students in Goal Attainment: An Empirical Assessment and Model for High Level Motivation and Goal Attainment
}

\author{
Paul Anderson \\ School of Business and Management, Azusa Pacific University \\ 901 East Alosta Avenue, Azusa, CA 91702 USA \\ Tel: 1-626-815-6000 E-mail: panderson@apu.edu \\ Orlando V. Griego \\ School of Business and Management, Azusa Pacific University \\ 901 East Alosta Avenue, Azusa, CA 91702 USA \\ Tel: 1-626-815-6000Ｅ-mail: ogriego@apu.edu \\ Roxanne Helm Stevens (Corresponding author) \\ School of Business and Management, Azusa Pacific University \\ 901 East Alosta Avenue, Azusa, CA 91702 USA \\ Tel: 1-626-815-6000 E-mail: rhelm@apu.edu
}

\begin{abstract}
Students at a private university in southern California took part in a study focusing on high level motivation and goal commitment. Using path analysis, this study mapped out two-paths. The first path to motivation and, therefore, goal commitment was through self-efficacy. The second path to goal commitment required a more supportive course. Spiritual, peer, family and leadership support combined to create a more encouraging sequence of action toward motivation and goal dedication.

There are many motivators that lead to goal completion. These motivators are generated from various influences - from peers, from family, from leaders, from faith, and from oneself. The purpose of this research is to look at motivation and goal achievement through the lens of personal motivators. The objective is to take a primarily business theory and apply it to college student marathon training.
\end{abstract}

Keywords: Education, Experiential, Student Motivation

\section{Literature Review}

Edwin Locke, American psychologist, was a pioneer in goal-setting theory publishing over 285 articles in various journals on topics such as work motivation and job satisfaction. Locke sought to understand how goals can influence performance. In 1990, Locke published, "A Theory of Goal Setting and Task Performance" with Gary Latham. The two developed what is now known as Goal Setting Theory. In business, Locke and Latham's (1990) goal setting theory has been used to predict job satisfaction. The authors argue that productivity of workers is significantly increased by high goals. Motivation, moreover, is the predecessor to goal accomplishment. Without motivation, goal failure can occur.

According to Locke and Latham's (2002) writings, when a goal is set at a difficult level a person is required to put forth more effort to meet it. This effort is motivation dependent. Goals, therefore, are motivation-based outcomes leading to personal satisfaction.

A key principle is that goals must be set, so that people can be motivated to achieve them. These cannot be easily achieved goals, but they must present a challenge to the person. Easily attained goals tend to correlate more with lower performance than difficult goals do. Also goals must be specific. Vague goals also tend to correlate with lower performance; effective goals tend to be very specific and rather challenging to achieve. Goals need to be able to motivate someone enough to spur them to meet ambitions, thereby helping the person focus on the objective. All efforts will be put towards achieving that objective and ultimately reaching the goal.

By setting an effective goal, individuals have a better chance of achieving their goal. However, many times, individuals set faulty goals. For example, students strive for "good grades," but they should set more specific goals, such as, striving for all A's and one B. Specific and difficult goals are more likely to yield results than a vague, easy goal. Locke and Latham (2002) found that people are motivated by clear goals and appropriate 
feedback. Working towards a goal provides a major source of motivation in actually reach the goal. In turn, this improves performance.

Motivation is achieved in many ways. Some are self-motivated and some are other-motivated. Vallerand (1997) provided a model of motivation which hypothesized about various motivational influences. Psychological needs must be met to create these needs. Vallerand (1997) referred to these motivational influences as "social factors." Vallerand and Losier (1999) claim these social factors can be applied to sport and physical activity.

There are numerous motivators outside of self. Patrick, et al. (1999) postulated that some of these social factors included peer support. They stated that peers help play a positive role in supporting the sustained participation towards a goal. Leadership also plays a vital role in motivating. The research pointing to leadership as an important factor in motivation is exhaustive. See Bass (1999) for a two decade review of the literature in this area. There is only tangential research in the area of personal faith and its relationship to motivation and goal commitment.

Some people, on the other hand, are self motivated. Bandura (2000), states that "Among the mechanisms of self-influence, none is more focal or pervading than belief of personal efficacy" (p. 2). He goes on to argue that unless people believe desired effects can be produced, they have little motivation to act. Consequently, motivators are rooted in the conviction that self-efficacy influences desired results.

\section{Research Question}

This research assessed high level goal attainment among business student using marathon training as an experimental variable. In doing so, various constructs were developed to assess participants in the training regimen. These constructs were either related to self-motivation or support-centered motivation. Those that were support-centered included peer, leadership, and spiritual support. Self-efficacy was used to measure self-motivation. Motivation and goal commitment were considered the dependent variables in the research.

\subsection{Research Questions}

1) What, if any, was the path or paths leading to motivation and goal commitment?

2) Were there any demographic differences (i.e., gender, ethnicity, etc.) with any of the proposed constructs?

\section{Research Design and Methods}

\subsection{Participants}

All research participants were enrolled as undergraduate students during the fall 2009 semester. The student population that participated in this study was enrolled at Azusa Pacific University (APU), located in Southern California. Azusa Pacific University has 4,874 full time undergraduate students (61\% female and 39\% male). Ethnic minority demographics include 36\% (Black, Asian or Pacific Islander, or Hispanic) of the student body profile. Approximately $67 \%$ of full time undergraduates receive need-based financial aid from the federal government and/or institution.

Sixty-two participants agreed to take part in the experimental study involving marathon training. Forty two (33.3\% male, $66.7 \%$ female) completed the training and ran the marathon. Thirty completed the survey $(71.4 \%$ response rate). The racial distribution of the students was $76.9 \%$ Caucasian and $23.1 \%$ minority. The training program was open to all university students, and included students in many academic majors, including Business, Liberal Studies, Nursing, Sociology, Biology, Applied Health, Athletic Training, Psychology, Political Science, Sports Psychology, and Cinema Arts.

\subsection{Procedures}

Participants were invited to participate in the study but were not required to take part. To reduce potential bias effects, the self-assessment instrument was administered over several days. Confidentiality was guaranteed. Moreover, the participants were informed of the purpose of the study, warned of any risks and inconveniences, explained the benefits of participating, and provided the opportunity to be removed from the study at any time.

\subsection{Instrumentation}

An instrument was developed covering six constructs: goal commitment, motivation, leadership support, mutual support, spiritual support, and self-efficacy. The original instrument contained 42 questions about the constructs, 6 demographic questions, and 4 open-ended questions. Some questions were omitted following inter-reliability ratings. Alphas indicated marginal to good reliability (alpha $=.62$ to .88 ) for all construct except one, motivation, which did not meet minimum expectations (alpha $=.45$ ).

The six constructs were designed to measure self-perceptions following the marathon training program. 
Following is a sample of the questions for each construct:

Goal-Commitment

- The goals I had on this challenge were demanding.

- I understood how my performance was measurable for this challenge.

- I expected positive results.

Self-Confidence

- I truly believed I faced this challenge realistically.

- I clearly understood my limitations throughout this challenge.

Leadership Support

- The coach led by "doing" rather than simply by "telling."

Mutual Support

- I was encouraged by fellow runners during this challenge.

- I was encouraged by friends and family during this challenge.

Spiritual Support

- I sought God's guidance throughout this challenge.

- I believe that God was by my side during this experience

Self-Efficacy

- I focused on my strengths not on my weaknesses.

- I had a strong sense of self-worth throughout this challenge.

The data were analyzed using SPSS 15.0 and AMOS 7.0. Analysis was completed using Cronbach's alpha and structural equation modeling as well as basic descriptive statistics.

\subsection{Design and Analysis}

Following reliability assessment of the constructs, a model was developed to evaluate the effects of marathon training (self-efficacy, leadership support, mutual support, and spiritual support) and the connection to motivation and goal commitment (see Fig. 1). In order to identify the model, several methods suggested by Joreskog and Sorbom (1986) were utilized: (1) consideration of alternative plausible models, (2) factor analysis, and (3) elimination of constructed variables. A factor analysis using Varimax was done to validate the grouping of the constructs. Overall, the factor analysis was congruent with the questions. In some questions, the factor analysis groupings were different from the grouped survey questions. Independent sample t-tests were accomplished to assess the differences in the various demographics (e.g., ethnicity, gender) on all six constructs.

The model suggests two potential paths to motivation and goal commitment - the "Self-efficacy" approach and "Supportive" approach. The Self-efficacy approach suggests that belief in oneself leads directly to motivation. Motivation then leads to goal commitment. The second path we call the Supportive approach. In the Supportive approach, three areas must work together in order to lead to motivation and eventually to goal commitment — spiritual support, mutual support, and leadership support. In both paths, goal commitment is the final outcome. The ea, eb, and ec are indicators of error effect.

\section{Findings}

AMOS 7.0 generates a chi-square statistic to determine significance and squared multiple correlation coefficients to determine variance. Because the chi-square test of absolute model fit is sensitive to sample size and non-normality in the underlying distribution of the input variables, various descriptive fit statistics to assess the overall fit of a model are provided. These include the Tucker-Lewis Index (TLI), the Comparative Fit Index (CFI), and the Root Mean Square Error of Approximation (RMSEA). Most commonly reported are the chi-square statistic and the squared multiple correlation coefficients. The null hypothesis under test is that the model fits the data, so one hopes to find a small, non-significant chi-square value for this test. For the model, the chi-square was $4.80,(\mathrm{p}=.68)$.

AMOS 7.0 further provides analysis in conjunction with the constructs (see Fig. 2). The covariance between spiritual, mutual, and leadership support ranges from .00 to .12. Too high a variance would indicate a multicollinearity problem. Table 1 indicates the means and standard deviations for each construct. Both 
motivation and goal commitment were smaller while self-efficacy, spiritual, mutual, and leadership support ranged from 3.25 to 3.88. The error variance is an estimate in this model and ranges from .06 to 14 .

The variance and Maximum Likelihood Estimates are one of the more telling statistics (see Table 2). If there is a direct connection to a construct as is the case from self-efficacy to motivation and motivation to goal commitment, then there is no variance estimate. The variance for the Support approach within the model ranges from .09 to .42 . The Maximum Likelihood Estimates indicates that when one area goes up by one standard deviation the effected construct goes up by an estimated amount. For example, Table 2 indicates that when self-efficacy goes up by 1 standard deviation, motivation increased by .17 standard deviations. The Support constructs increased .03 to .17. Goal commitment increased by .29 when motivation goes up by 1 standard deviation.

Further analysis was done to compare ethnicity, academic major, previous running experience, and training preference (running alone or in a group) across the various constructs, using independent samples t-tests. There were no significant results from this analysis.

\section{Conclusions}

The research indicates a two-path model toward high level motivation and, ultimately, goal commitment. The first is self-efficacy leading to motivation and then to goal commitment. Self-efficacy is defined as one's beliefs about their capabilities to produce designated levels of performance that exercise influence over events that affect their lives. Self-efficacy beliefs determine how people feel, think, motivate themselves and behave. In this case, the self-efficacy group completed a marathon. Those rating themselves high in self-efficacy did not rely on the spiritual, mutual, or leadership support to complete the goal. Interestingly, cross tabulations indicated that self-efficacy was not related to having training previously or training alone.

Bandura (1994) notes that, "a strong sense of efficacy enhances human accomplishment and personal well-being in many ways". People with high assurance in their capabilities approach difficult tasks as challenges to be mastered rather than as threats to be avoided." The training, and subsequent experimental goal accomplishment, suggests the respondents with high self-efficacy was a significant path to motivation, and motivation led to completing the goal.

The second path to goal completion required a more supportive course. In concert, spiritual, mutual, and leadership support worked as a means of sustaining participants toward a goal commitment. This path required more encouragement from others (i.e., peers, family, friends, and leaders) and from faith. Such encouragement leads to motivation and goal commitment. Lastly, we found the model to be statistically valid only if all three components (spiritual, mutual and leadership) were included in the path analysis. In other words, respondents indicated that spiritual, mutual, and leadership support needed to work in conjunction in order to achieve a motivational state and, ultimately, complete the goal of running a marathon.

Results of this study are generally positive and have important implications for goal attainment. Future research in this area would be advantageous, however. For instance, using a control group would solidify the validity of the study. Moreover, redesign on the motivation construct should be considered in order to achieve a Cronbach's Alpha of .70 or higher. Though this study was done using participants in a marathon, it would benefit from replication with another high-level goal attainment task. In addition, the further conceptual ideas could be explored besides self-efficacy, spiritual support, mutual support, and leadership support to determine if other areas lead to goal attainment.

\section{References}

Azusa Pacific University. (2009). Financial aid. In Office of Institutional Research Common Data Set: 2009-2010. Retrieved January 9, 2010 from http://www.apu.edu/ir/commondata/2008/h/

Azusa Pacific University. (2009). Enrollment and persistence. In Office of Institutional Research Common Data Set: 2009-2010. Retrieved January 9, 2010 from http://www.apu.edu/ir/commondata/2008/b/

Barth, M., Godemann, J., Rieckmann, M. \& Stoltenberg, U. (2007). Developing key competencies for sustainable development in higher education. International Journal of Sustainability in Higher Education, 8(4), 416-430.

Bandura, A. (1994). Self-efficacy. In V. S. Ramachaudran (Ed.), Encyclopedia of human behavior (Vol. 4, pp. 71-81). New York: Academic Press. (Reprinted in H. Friedman [Ed.], Encyclopedia of mental health. San Diego: Academic Press, 1998).

Bandura, A. (2000). Cultivate self-efficacy for personal and organizational effectiveness. In E. A. Locke (Ed.), 
Handbook of principles of organization behavior. (pp. 120-136). Oxford, UK: Blackwell.

Bass. B.M. (1999). Two decades of research and development in transformational leadership. European Journal of Work and Organizational Psychology, 8 (1), pp. 9 - 32.

Joreskog, K.G. \& Sorbom, D. (1993). LISREL 8: Structural equation modeling with the simplis command language. Scientific Software International Inc., Chicago, IL.

Locke, E. A. and Latham, G. P. (1990). A theory of goal setting and task performance. Englewood Cliffs, NJ: Prentice Hall.

Locke, E. A., \& Latham, G. P. (2002). Building a Practically Useful Theory of Goal Setting and Task Motivation: A 35-year Odyssey[electronic version]. American Psychologist, 57, 705-717.

Patrick, H., Ryan A.M., Alfeld-Liro, C., Fredricks, J.A., Hruda, L.Z. \& Eccles, J.S. (1999). Adolescents' commitment to developing talent: the role of peers in continuing motivation for sports and the arts. Journal of Youth and Adolescence 28 (6), pp. 741-763.

Vallerand, R.J. (1997). Toward a hierarchical model of intrinsic and extrinsic motivation. In M. Zanna (Ed.), Advances in experimental social psychology (pp. 271 360). New York: Academic Press.

Vallerand, R.J., \& Losier, G.F. (1999). An integrative analysis of intrinsic and extrinsic motivation in sport. Journal of Applied Sport Psychology, 11, 142 169.

Table 1. Means and Standard Deviations

\begin{tabular}{llll}
\hline & N & Mean & SD \\
\hline Self-efficacy & 26 & 3.25 & .37 \\
Spiritual support & 26 & 3.30 & .66 \\
Mutual support & 26 & 3.58 & .58 \\
Leadership support & 25 & 3.88 & .30 \\
Motivation & 26 & 3.79 & .30 \\
Goal commitment & 26 & 3.58 & .33 \\
\hline
\end{tabular}

Table 2. Variance and Maximum Likelihood Estimates

\begin{tabular}{lll}
\hline & Variance & MLI \\
\hline Self-efficacy to Motivation & n.a. & .17 \\
Spiritual support to Motivation & .42 & .17 \\
Mutual support to Motivation & .32 & .12 \\
Leadership support to Motivation & .09 & .03 \\
Motivation to Goal commitment & n.a & .29 \\
\hline
\end{tabular}




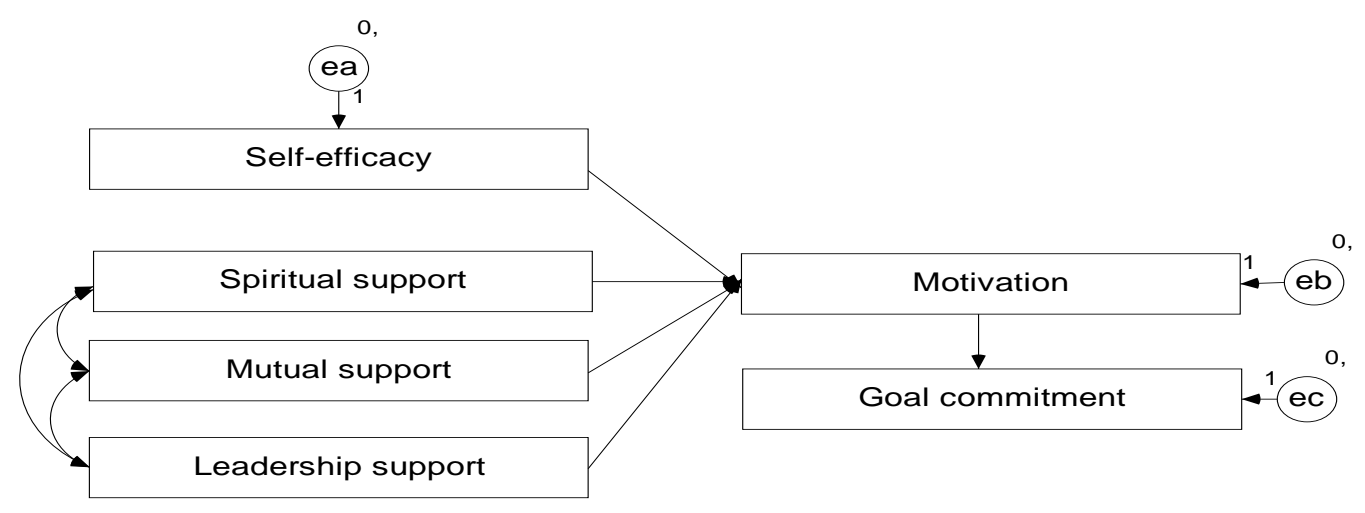

Figure 1. Effective Motivation and Goal Commitment Model

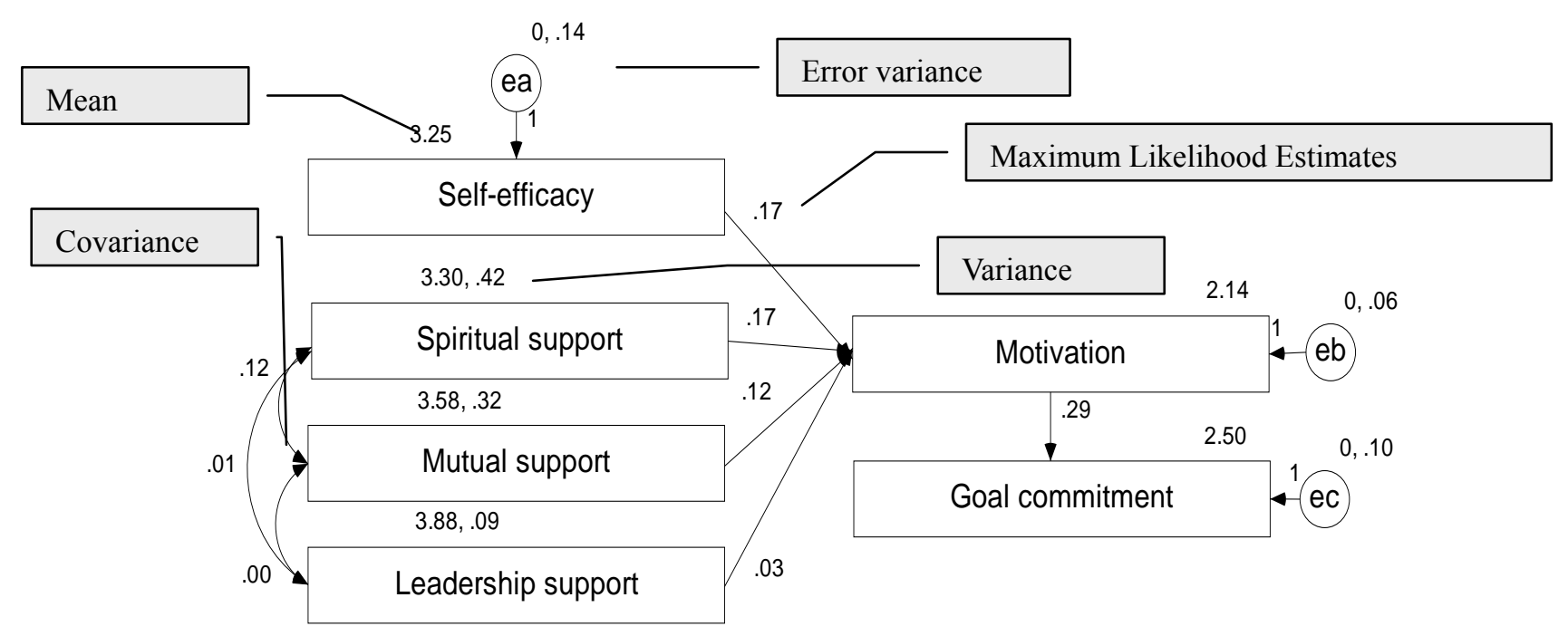

Figure 2. Effective Motivation and Goal Commitment Model with Analysis 